\title{
Approach-related complications after decompression for cervical ossification of the posterior longitudinal ligament
}

\author{
Mario J. Cardoso, M.D., D.C., Tyler R. Koski, M.D., Aruna Ganju, M.D., \\ AND JoHN C. LIU, M.D. \\ Department of Neurosurgery, Northwestern Memorial Hospital, Chicago, Illinois
}

\begin{abstract}
The surgical management of compressive cervical ossification of the posterior longitudinal ligament (OPLL) can be challenging. Traditionally, approach indications for decompression of cervical spondylotic myelopathy have been used. However, the postoperative complication profile after cervical OPLL decompression is unique and may require an alternative approach paradigm. The authors review the literature on approach-related OPLL complications and suggest a management strategy for patients with single- or multiple-segment OPLL with or without greater than 50\% canal stenosis. (DOI: 10.3171/2011.1.FOCUS10278)
\end{abstract}

KEY WORDS $\quad$ ossification of the posterior longitudinal ligament $\quad \bullet \quad$ decompression
cervical myelopathy $\quad$ complication

$\mathrm{O}$ SSIFICATION of the posterior longitudinal ligament can be a problematic cause of compressive cervical myelopathy. Although more commonly diagnosed in Japan, OPLL is a source of compressive cervical myelopathy within the US and may have an incidence as high as $25 \%$. $^{13,16}$

When determining a cervical approach for this condition, several important questions are asked, such as: 1) what is the cervical alignment, 2) is the deformity fixed or flexible, 3 ) is the pathology segmental or extensive ( $>3$ levels), 4) is there instability or subluxation, and 5) what is the patient's medical status? These questions aid in determining the optimal surgical approach and minimizing postoperative complications. However, decompression of the spinal cord in the setting of OPLL has a different complication profile and the preferred approach and/ or technique remains controversial. This complication profile that includes CSF fistula, neurological injury, and myelopathic progression may need to be given greater thought during the decision process. In the following paper, we review the surgical OPLL literature and evaluate the complications associated with the different approaches and techniques, to better formulate a surgical strategy for the operative management of OPLL compressive cervical myelopathy.

\footnotetext{
Abbreviation used in this paper: OPLL = ossification of the posterior longitudinal ligament.
}

\section{CSF Leaks and Fistulas}

\section{Anterior Approach}

Traditionally, cervical corpectomy and resection of the OPLL has been the method of choice within the US. The incidence of dural tears and CSF fistulas after cervical corpectomy for all pathologies has been reported to be between $0 \%$ and $8 \%{ }^{10,12,26,28}$ However, the incidence of a CSF leak after anterior cervical OPLL resection is much higher (between 6.7\% and 31.8\%).,15,16,38 Dural tears after OPLL resection tend to be problematic. Repair techniques employed include gelatin sponges, patch grafts, fibrin glue, primary suture closure, and CSF diversion. Despite these techniques, the incidence of fistula and pseudomeningocele formation remains high $(4.6 \%-22.7 \%))^{12,38}$ In all reported cases, these fistulas ultimately require some form of temporary or permanent CSF diversion.

Mizuno and Nakagawa ${ }^{31}$ reported a $20 \%$ incidence of CSF leak (21 of 107 patients) after anterior cervical decompression for OPLL. All 21 cases were repaired using a muscle graft, Oxycel, and fibrin glue. Nevertheless, more than $33 \%$ of these patients required CSF diversion via a lumbar drain for 1 week.

Several surgical techniques have been used to prevent dural tears. One such technique is the cervical "floating method" of OPLL decompression. The technique involves thinning the OPLL and isolating it from the remainder of the involved cervical vertebrae. In a retrospective review, 
Matsuoka et al. ${ }^{27}$ reported the long-term outcomes in 63 patients after anterior cervical decompression using the floating method. These investigators reported the incidence of a CSF leak or fistula to be 5.1\%. Similarly, Joseph et al. ${ }^{21}$ in a larger retrospective study of 144 patients reported a low incidence of CSF leak (6.3\%) after anterior cervical OPLL decompression using the same floating method. In this study, the incidence of CSF leak increased from 5.6\% and $5.3 \%$ for a 1- and 2-level corpectomy, respectively, to $16.7 \%$ for a 3-level corpectomy.

Indirect decompression and fusion has also been described as an alternative strategy for surgically managing OPLL-induced cervical myelopathy while avoiding the potential risk for a CSF leak. Onari et al. ${ }^{34}$ reported long-term results in 30 patients treated with an anterior cervical interbody fusion without resection of the OPLL. The majority of the patients were classified as having an excellent or good outcome and there were no CSF leaks.

\section{Posterior Approach}

Posterior cervical decompressions, laminoplasty, and laminectomy, in patients with or without OPLL, have a low incidence of durotomy. Even in the presence of an ossified ligamentum flavum, the decompression can often be performed without risk of a CSF leak. Alternatively, the resection of postlaminectomy compressive pseudomembrane can be problematic and often is associated with a CSF leak.

Both radiographic and clinical studies have demonstrated a low incidence of CSF leak/fistula after posterior cervical decompression. In a retrospective review of 400 cervical CT scans in postlaminectomy patients, Teplick et al. ${ }^{42}$ noted only 8 patients (2\%) with a pseudomeningocele. Miyazaki and Kirita ${ }^{30}$ noted no CSF leaks in a retrospective review of 155 patients who underwent a laminectomy for OPLL. Similarly, Chiba et al. ${ }^{9}$ noted a very low incidence of dural tears after performing an expansive laminoplasty for OPLL.

\section{Neurological Injuries and C-5 Nerve Palsy}

\section{Anterior Approach}

Postoperative C-5 nerve palsy after surgery for compressive cervical myelopathy is a well-known complication that is poorly understood. The incidence of C-5 nerve palsy after anterior cervical decompression has been reported to occur in $1.6 \%-12.1 \%$ of patients, with an average incidence of $4.3 \%{ }^{35}$ Half of these patients develop sensory deficits and/or intractable C-5 dermatome pain. The majority of C-5 nerve palsies are unilateral. In a review of the literature, Sakaura et al..$^{35}$ cited an incidence of $8 \%$ for bilateral C-5 palsies. In the majority of patients, the palsy appears within the 1st week but may appear as late as 4 weeks after surgery.

As previously mentioned, the origin of C-5 palsy is unclear, but direct injury with dural resection of OPLL has been reported. Mizuno and Nakagawa ${ }^{31}$ reported 3 C-5 palsies that occurred immediately postoperatively. All 3 C-5 palsies were associated with a dural tear while removing extensive lateral recess OPLL. Two of the pal- sies were transient and the other was permanent. The authors believed that the palsies were the result of a direct nerve root injury during OPLL dissection. Belanger et al. ${ }^{6}$ also noted immediate postoperative deltoid weakness in 2 patients in whom the dura was violated in proximity to the C-5 nerve root. Although no obvious compression of the nerve root could be demonstrated, the mechanical decompression may have resulted in a neurapraxia of the C-5 nerve root. Both patients eventually recovered full function.

Preserving the OPLL while decompressing the spinal canal does not appear to eliminate the risk of C-5 palsy. Matsuoka et al. ${ }^{27}$ reported an incidence of $9.5 \%$ after using the "floating method" for decompressing the anterior cervical spine. None of the deficits were the result of direct injury. Nonetheless, C-5 palsy was detected in patients immediately or shortly after surgery.

Interestingly, patients who undergo anterior indirect decompression and fusion are not at risk for C-5 palsy. Onari et al. ${ }^{34}$ reported long-term results for 30 patients with OPLL-induced cervical myelopathy. All of the patients were treated using an anterior cervical fusion without OPLL decompression, and none of the patients developed C-5 nerve palsy. However, $80 \%$ of the patients had good to excellent long-term results.

\section{Posterior Approach}

The incidence of C-5 nerve palsy after posterior cervical decompression for OPLL is similar to that of spondylotic cervical myelopathy. The incidence ranges from $0 \%$ to $30 \%$, with an average of $4.7 \% .{ }^{27}$ Complications associated with iatrogenic spinal cord injury and postoperative spinal cord compression from epidural hematoma are also technique dependent and not related to the cause of compression.

Although neurological recovery after laminoplasty and laminectomy with and without fusion can be achieved, there is concern that there is a critical point of central canal compression with OPLL in which anterior decompression may be preferred. ${ }^{6,39,41,45}$ Iwasaki et al. ${ }^{20}$ reviewed data for 66 patients after laminoplasty for OPLL with a mean follow-up period of 10 years. They noted a poor recovery rate in patients with $60 \%$ or higher occupying ratio of the central canal. These patients accounted for nearly $30 \%$ of the patients with poor outcomes due to their cervical OPLL. The remainder of the poor outcomes were attributed to change in cervical alignment, hillshaped OPLL, and postoperative progression of OPLL.

Tani et al..$^{41}$ compared the relative safety of anterior corpectomy versus laminoplasty for decompression of massive OPLL (> 50\% canal compression). As compared with laminoplasty, patients treated with a corpectomy were noted to have significantly better functional results and no postoperative neurological complications. Patients treated with a laminoplasty were noted to have significant neurological deterioration. One-third of the neurological deteriorations occurred immediately after surgery. Similarly, Baba et al. ${ }^{3}$ noted poor long-term neurological results after laminoplasty in patients with OPLL and greater than $50 \%$ stenosis. 


\section{Long-Term Neurological Outcome and Deterioration}

The primary goal of cervical decompression is clinical stabilization. However, clinical improvement or decline may occur. Patients with severe clinical symptoms are more likely to benefit from surgery, ${ }^{5,25,36}$ whereas patients with mild symptoms will tend to have their symptoms stabilize. Despite surgical intervention, patients may still develop progression of their disease.

Both anterior and posterior surgical approaches can achieve good to excellent clinical results over a 2- to 4-year follow-up period. ${ }^{6-8}$ However, benefits may not be sustained due to comorbidities in the elderly and to OPLL progression. Anterior decompression has been shown to maintain adequate long-term outcomes more than 10 years postoperatively.11,27 Similarly, posterior decompression with open-door laminoplasty has demonstrated satisfactory long-term outcomes for more than 10 years. ${ }^{9}$ Regardless of technique, patients tend to initially improve and sustain these results for 3-5 years and subsequently show some clinical decline over the following 5-10 years.

Although OPLL progression does occur, it may only account for a small percentage of the clinical decline appreciated in patients. Matsuoka et al. ${ }^{27}$ reported the longterm outcomes in 63 patients after the "floating method" of anterior cervical decompression; after 10 years, 36 patients $(57 \%)$ demonstrated progression of their OPLL beyond the operative field. However, only 3 of these patients demonstrated clinical deterioration. Onari et al. ${ }^{34}$ reported progression of OPLL in 26 of 30 patients. Interestingly, the neurological status of these patients did not correlate with the progression of OPLL. Twenty-one patients did not demonstrate any change in neurological status, and 5 patients improved over the course of the study. Of the 4 patients who demonstrated a neurological decline, none were the result of cervical progression of OPLL.

\section{Cervical Kyphosis}

Performing a posterior cervical laminectomy does not immediately destabilize the cervical spine. The posterior cervical exposure results in denervation and atrophy of the posterior cervical musculature, consequently increasing the anterior vertebral body compressive load, promoting kyphosis. The kyphotic alignment drapes the spinal cord over the posterior aspect of the vertebral bodies and may contribute to neurological decline.

The incidence of postoperative kyphosis after multilevel cervical laminectomy has been reported to be $20 \% .{ }^{23}$ However, postoperative kyphosis does not appear to correlate with clinical progression. Miyazaki and Kiri$\operatorname{ta}^{30}$ followed 155 patients after a laminectomy for OPLL compressive myelopathy, with an average follow-up duration of 4 years. These authors noted an increase in lordosis in $7 \%$ of patients, a decrease in lordosis in $16 \%$, and an increase in kyphosis in $17 \%$. No correlation with clinical outcome was found.

Laminectomy and instrumented fusion is believed to prevent postlaminectomy kyphosis and potentially improve cervical lordosis. Chen et al., ${ }^{8}$ in a retrospective radiographic review of 83 patients with OPLL compressive myelopathy, reported improved postoperative lordosis after cervical laminectomy and instrumented fusion. In addition, there was a correlation between cervical lordosis and a better prognosis. However, there was also a correlation between improved lordosis and the incidence of C-5 nerve root palsy.

It is believed that a better decompression can be obtained in patients with a lordotic cervical spine than in a straight or kyphotic spine. An advantage of subaxial laminoplasty is that it prevents postoperative kyphosis. . $^{18,19,24,37}$ Seichi et al. ${ }^{37}$ reported 10 -year follow-up data in 35 patients after double-door laminoplasty for OPLL compressive cervical myelopathy. None of the patients developed a postoperative kyphotic deformity, but the authors did note a decrease in range of motion from $36^{\circ}$ to $8^{\circ}$ in flexion/extension. No neurological deterioration was attributed to the decompression or cervical alignment.

The preservation of the semispinalis attachment at $\mathrm{C}-2$ is considered essential in the prevention of postlaminoplasty kyphosis. Takeshita et al $^{40}$ demonstrated that if C-2 was incorporated into the laminoplasty, there was an increase in postoperative kyphosis. However, there was no significant difference in neurological outcome at 4-years' follow-up.

\section{Discussion}

Determining the optimal approach for decompression of OPLL-induced cervical myelopathy can be problematic. Traditionally we consider cervical alignment, flexibility, instability, and patient medical status to determine the optimal approach for this condition. However, cervical OPLL compression has a unique complication profile as compared with typical spondylotic myelopathy.

Durotomy is a well-known complication of spinal canal decompression that is often easily managed with primary repair. However, anterior cervical repair of a durotomy can be challenging. In the setting of OPLL, this often requires a dural substitute to be sutured to the tenuous surrounding dura followed by temporary CSF diversion. ${ }^{1,15,16,38}$ To minimize the risk of durotomy, various surgical techniques have been adopted that do not involve OPLL resection. ${ }^{21,27,34}$ Irrespective of technique, there is a direct correlation between the number of OPLL segments decompressed and the risk of durotomy. ${ }^{21,27}$ One- and 2 -segment decompression represents a modest risk that is similar to that of multilevel posterior decompression. Given that both laminectomy and laminoplasty are better suited for multilevel ( $>3$ levels) decompression, the durotomy risk associated with anterior 1- and 2-segment decompression is reasonable. Patients requiring greater than a 2-level decompression should be considered for a laminectomy with or without fusion or a laminoplasty.

Iatrogenic neurological injury is a constant concern for a spine surgeon. Preoperative planning and proper surgical technique help to minimize potential injury. Nevertheless, postoperative C-5 nerve root palsies occur and most often without direct insult. Approach does not appear to play a role in the incidence or recovery of a C-5 palsy. ${ }^{31,35}$ Direct decompression appears to have a 
mechanical effect on the nerve tension, resulting in palsy. Interestingly, patients who undergo indirect decompression do not appear to be at risk. ${ }^{34}$

Approach-specific complications irrespective of OPLL also need to be considered. Anterior approaches can be complicated by dysphasia, recurrent laryngeal nerve injury, and increased risk of pseudarthrosis with multilevel

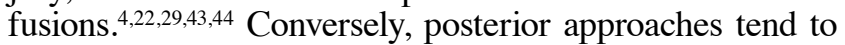
have an increased risk for infection, increased postoperative neck pain, and postlaminectomy kyphosis. ${ }^{2,17,32,33}$ The incidence of epidural hematoma resulting in spinal cord compression is similar for both approaches. ${ }^{8,9}$ The reported overall incidence of epidural hematoma is $1 \%$, slightly less than that reported for posterior cervical decompression..$^{14}$ In general, cervical spine complications are not well tolerated by the elderly. However, the risks associated with a posterior approach may be better endured.

Certainly, approach-related complications should be taken into account when considering the surgical management of cervical OPLL. In addition, the OPLL morphology and extent of canal compromise should be evaluated carefully. While clinical outcomes appear to be similar for both anterior and posterior approaches, patients with greater than 50\% OPLL canal compromise or "hill-shaped" OPLL compression have improved outcomes after anterior decompression. . $, 23,24^{2}$

When determining a surgical approach for OPLL decompression, the following considerations are made: 1) number of decompression segments; 2) OPLL morphology and extent of spinal canal compromise; and 3) patient age and comorbidities. Whether an anterior or posterior approach is chosen, patients should be made aware of the short- and long-term complications associated with this difficult disease to make the best decision with their surgeon.

\section{Conclusions}

Anterior cervical decompression is associated with a higher incidence of CSF leaks and fistulas. However, using the floating method of anterior decompression decreases the incidence of CSF leaks for 1- and 2-segment OPLL. Posterior decompression through laminoplasty or laminectomy with or without fusion should be considered in patients with less than 50\% OPLL stenosis and without hill-shaped OPLL compression.

\section{Disclosure}

Dr. Liu serves as a consultant to Medtronic and DePuy.

Author contributions to the study and manuscript preparation include the following. Conception and design: Koski, Ganju, Liu. Acquisition of data: Cardoso. Analysis and interpretation of data: all authors. Drafting the article: Cardoso. Critically revising the article: Cardoso, Liu. Reviewed final version of the manuscript and approved it for submission: all authors. Administrative/technical/ material support: all authors. Study supervision: Koski, Liu.

\section{References}

1. Abe H, Tsuru M, Ito T, Iwasaki Y, Koiwa M: Anterior decompression for ossification of the posterior longitudinal ligament of the cervical spine. J Neurosurg 55:108-116, 1981
2. Albert TJ, Vacarro A: Postlaminectomy kyphosis. Spine 23: 2738-2745, 1998

3. Baba H, Imura S, Kawahara N, Nagata S, Tomita K: Osteoplastic laminoplasty for cervical myeloradiculopathy secondary to ossification of the posterior longitudinal ligament. Int Orthop 19:40-45, 1995

4. Bazaz R, Lee MJ, Yoo JU: Incidence of dysphagia after anterior cervical spine surgery: a prospective study. Spine 27: 2453-2458, 2002

5. Bednarik J, Kadanka Z, Vohánka S, Stejskal L, Vlach O, Schröder R: The value of somatosensory- and motor-evoked potentials in predicting and monitoring the effect of therapy in spondylotic cervical myelopathy. Prospective randomized study. Spine 24:1593-1598, 1999

6. Belanger TA, Roh JS, Hanks SE, Kang JD, Emery SE, Bohlman HH: Ossification of the posterior longitudinal ligament. Results of anterior cervical decompression and arthrodesis in sixty-one North American patients. J Bone Joint Surg Am 87:610-615, 2005

7. Chen Y, Chen D, Wang X, Lu X, Guo Y, He Z, et al: Anterior corpectomy and fusion for severe ossification of posterior longitudinal ligament in the cervical spine. Int Orthop 33:477-482, 2009

8. Chen Y, Guo Y, Chen D, Wang X, Lu X, Yuan W: Long-term outcome of laminectomy and instrumented fusion for cervical ossification of the posterior longitudinal ligament. Int Orthop 33:1075-1080, 2009

9. Chiba K, Ogawa Y, Ishii K, Takaishi H, Nakamura M, Maruiwa H, et al: Long-term results of expansive open-door laminoplasty for cervical myelopathy-average 14-year follow-up study. Spine 31:2998-3005, 2006

10. Edwards CC II, Heller JG, Murakami H: Corpectomy versus laminoplasty for multilevel cervical myelopathy: an independent matched-cohort analysis. Spine 27:1168-1175, 2002

11. Emery SE, Bohlman HH, Bolesta MJ, Jones PK: Anterior cervical decompression and arthrodesis for the treatment of cervical spondylotic myelopathy. Two to seventeen-year followup. J Bone Joint Surg Am 80:941-951, 1998

12. Epstein N: Anterior approaches to cervical spondylosis and ossification of the posterior longitudinal ligament: review of operative technique and assessment of 65 multilevel circumferential procedures. Surg Neurol 55:313-324, 2001

13. Epstein $\mathrm{N}$ : The surgical management of ossification of the posterior longitudinal ligament in 51 patients. J Spinal Disord 6:432-455, 1993

14. Glotzbecker MP, Bono CM, Wood KB, Harris MB: Postoperative spinal epidural hematoma: a systematic review. Spine 35:E413-E420

15. Hanai K, Inouye Y, Kawai K, Tago K, Itoh Y: Anterior decompression for myelopathy resulting from ossification of the posterior longitudinal ligament. J Bone Joint Surg Br 64: 561-564, 1982

16. Harsh GR IV, Sypert GW, Weinstein PR, Ross DA, Wilson CB: Cervical spine stenosis secondary to ossification of the posterior longitudinal ligament. J Neurosurg 67:349-357, 1987

17. Herkowitz HN: A comparison of anterior cervical fusion, cervical laminectomy, and cervical laminoplasty for the surgical management of multiple level spondylotic radiculopathy. Spine 13:774-780, 1988

18. Hirabayashi K, Toyama Y, Chiba K: Expansive laminoplasty for myelopathy in ossification of the longitudinal ligament. Clin Orthop Relat Res (359):35-48, 1999

19. Inoue A, Ikata T, Katoh S: Spinal deformity following surgery for spinal cord tumors and tumorous lesions: analysis based on an assessment of the spinal functional curve. Spinal Cord 34:536-542, 1996

20. Iwasaki M, Okuda S, Miyauchi A, Sakaura H, Mukai Y, Yonenobu K, et al: Surgical strategy for cervical myelopathy due to ossification of the posterior longitudinal ligament: Part 1: 


\section{Approach-related complications after cervical OPLL decompression}

Clinical results and limitations of laminoplasty. Spine 32: 647-653, 2007

21. Joseph V, Kumar GS, Rajshekhar V: Cerebrospinal fluid leak during cervical corpectomy for ossified posterior longitudinal ligament: incidence, management, and outcome. Spine 34: 491-494, 2009

22. Jung A, Schramm J, Lehnerdt K, Herberhold C: Recurrent laryngeal nerve palsy during anterior cervical spine surgery: a prospective study. J Neurosurg Spine 2:123-127, 2005

23. Kaptain GJ, Simmons NE, Replogle RE, Pobereskin L: Incidence and outcome of kyphotic deformity following laminectomy for cervical spondylotic myelopathy. J Neurosurg 93 (2 Suppl):199-204, 2000

24. Kawaguchi Y, Kanamori M, Ishihara H, Ohmori K, Nakamura H, Kimura T: Minimum 10-year followup after en bloc cervical laminoplasty. Clin Orthop Relat Res (411):129-139, 2003

25. Lees F, Turner JW: Natural history and prognosis of cervical spondylosis. BMJ 2:1607-1610, 1963

26. Macdonald RL, Fehlings MG, Tator $\mathrm{CH}$, Lozano A, Fleming JR, Gentili F, et al: Multilevel anterior cervical corpectomy and fibular allograft fusion for cervical myelopathy. J Neurosurg 86:990-997, 1997

27. Matsuoka T, Yamaura I, Kurosa Y, Nakai O, Shindo S, Shinomiya K: Long-term results of the anterior floating method for cervical myelopathy caused by ossification of the posterior longitudinal ligament. Spine 26:241-248, 2001

28. Mayr MT, Subach BR, Comey CH, Rodts GE, Haid RW Jr: Cervical spinal stenosis: outcome after anterior corpectomy, allograft reconstruction, and instrumentation. J Neurosurg 96 (1 Suppl): 10-16, 2002

29. Mendoza-Lattes S, Clifford K, Bartelt R, Stewart J, Clark CR, Boezaart AP: Dysphagia following anterior cervical arthrodesis is associated with continuous, strong retraction of the esophagus. J Bone Joint Surg Am 90:256-263, 2008

30. Miyazaki K, Kirita Y: Extensive simultaneous multisegment laminectomy for myelopathy due to the ossification of the posterior longitudinal ligament in the cervical region. Spine 11: 531-542, 1986

31. Mizuno J, Nakagawa H: Outcome analysis of anterior decompressive surgery and fusion for cervical ossification of the posterior longitudinal ligament: report of 107 cases and review of the literature. Neurosurg Focus 10(4):E6, 2001

32. Olsen MA, Mayfield J, Lauryssen C, Polish LB, Jones M, Vest $\mathrm{J}$, et al: Risk factors for surgical site infection in spinal surgery. J Neurosurg 98 (2 Suppl):149-155, 2003

33. Olsen MA, Nepple JJ, Riew KD, Lenke LG, Bridwell KH, Mayfield J, et al: Risk factors for surgical site infection following orthopaedic spinal operations. J Bone Joint Surg Am 90:62-69, 2008

34. Onari K, Akiyama N, Kondo S, Toguchi A, Mihara H, Tsuchiya T: Long-term follow-up results of anterior interbody fusion applied for cervical myelopathy due to ossification of the posterior longitudinal ligament. Spine 26:488-493, 2001

35. Sakaura H, Hosono N, Mukai Y, Ishii T, Yoshikawa H: C5 palsy after decompression surgery for cervical myelopathy: review of the literature. Spine 28:2447-2451, 2003

36. Sampath P, Bendebba M, Davis JD, Ducker TB: Outcome of patients treated for cervical myelopathy. A prospective, multicenter study with independent clinical review. Spine 25:670676,2000

37. Seichi A, Takeshita K, Ohishi I, Kawaguchi H, Akune T, Anamizu Y, et al: Long-term results of double-door laminoplasty for cervical stenotic myelopathy. Spine 26:479-487, 2001

38. Smith MD, Bolesta MJ, Leventhal M, Bohlman HH: Postoperative cerebrospinal-fluid fistula associated with erosion of the dura. Findings after anterior resection of ossification of the posterior longitudinal ligament in the cervical spine. J Bone Joint Surg Am 74:270-277, 1992

39. Sodeyama T, Goto S, Mochizuki M, Takahashi J, Moriya H: Effect of decompression enlargement laminoplasty for posterior shifting of the spinal cord. Spine 24:1527-1532, 1999

40. Takeshita K, Seichi A, Akune T, Kawamura N, Kawaguchi H, Nakamura K: Can laminoplasty maintain the cervical alignment even when the C2 lamina is contained? Spine 30:12941298, 2005

41. Tani T, Ushida T, Ishida K, Iai H, Noguchi T, Yamamoto H: Relative safety of anterior microsurgical decompression versus laminoplasty for cervical myelopathy with a massive ossified posterior longitudinal ligament. Spine 27:2491-2498, 2002

42. Teplick JG, Peyster RG, Teplick SK, Goodman LR, Haskin ME: CT Identification of postlaminectomy pseudomeningocele. AJR Am J Roentgenol 140:1203-1206, 1983

43. Wang JC, McDonough PW, Endow KK, Delamarter RB: Increased fusion rates with cervical plating for two-level anterior cervical discectomy and fusion. Spine 25:41-45, 2000

44. Wang JC, McDonough PW, Kanim LE, Endow KK, Delamarter RB: Increased fusion rates with cervical plating for threelevel anterior cervical discectomy and fusion. Spine 26:643647, 2001

45. Yamazaki A, Homma T, Uchiyama S, Katsumi Y, Okumura $\mathrm{H}$ : Morphologic limitations of posterior decompression by midsagittal splitting method for myelopathy caused by ossification of the posterior longitudinal ligament in the cervical spine. Spine 24:32-34, 1999

Manuscript submitted November 15, 2010.

Accepted January 10, 2011.

Address correspondence to: Mario J. Cardoso, M.D., D.C., Northwestern Memorial Hospital, Department of Neurosurgery, 251 East Huron Street, Chicago, Illinois 60611. email: mtcardoso@ comcast. net. 